\title{
The Effectiveness of Sustainable Construction Materials by Using U-Shaped Composite Spacer Block (UCop)
}

\author{
Mohamed Bin Saim ${ }^{1}$, Saliza Binti Abdullah Rahman ${ }^{2}$, Nurul Aqilah Binti Ibrahim ${ }^{3}$ \\ (Civil Engineering Department, Graduate School of Civil Engineering, The Polytechnic of Kota Kinabalu, Sabah, \\ Malaysia)
}

\begin{abstract}
Nowadays in construction development, the needs of construction materials that have a unique reinforced concrete design with good quality, reasonable market price, and easy installation techniques has been prioritized. Therefore, this study aimed to produce an alternative new construction material that can fulfill the requirements.

The U-shaped composite spacer block (UCop) through the production of Cement Bonded Particle Board (CBPB) as a specimen block was produced from the wood waste of carpentry work combined with Shorea spp. (Seraya red and white) particle size approximately $0.4 \mathrm{~mm}-2.00 \mathrm{~mm}$. Then it was mixed together with Portland cement by using a ratio 1:2.5. The mixture was then added with Ammonia Chloride (A12SO4) and Calcium Chloride $(\mathrm{CaCl} 2)$ act as additives for this product. The physical and mechanical tests were conducted in this study. The results were showed that the thickness expansion was achieved an average of $1.79 \%$, which was passed the minimum requirement of MS934:1986 standards. However, the flexural strength did not meet the minimum standards. The poor mixing technique was attributed to the results. However, UCop still could contribute as an alternative solution in ease the concrete pouring process using a special binder, giving the spacer block any resistance to formwork of columns or beams is filled with concrete. The high-impact innovations of this product in construction such as it can help the process to be more efficient and to reduce construction costs, next indirectly preserve the nature.
\end{abstract} board

Key words: $U C o p$, composite, spacer block, construction material, wood waste, wood cement bonded particle

\section{Introduction}

Wood-cement composite is a new opportunity for recycling post-consumer wood and chemically treated wood fiber in the constructed building and produce sound absorbing products. The technology employed throughout the world to produce stay-inplace insulated wall forms, structural panels, acoustical treatments, and highway sound barriers [1]. The development and use of wood-cement composites attest to their attraction as building materials. In addition to the resistance of weather, these materials have a special attraction to be used in warm, humid climates where termites and decay are a major concern.

Cement binder provides a durable surface as it can be easily embossed and colored for made an attractive, low-maintenance finished product [2]. A variety of design innovation have been produced spacer blocks as issued by the company Structural Components in East Longmeadow, Massachusetts, United States are made of PVC plastic and named
RE-RINGS [3]. Where as basic research is needed to assess for developing engineered products feasibility which will exploit the unique properties of woodcement composites [4].

This study aims to produce a sample of $\mathrm{U}$ shaped composite spacer block (UCop) that takes into account in terms of quality and to lower cost through the production of Cement Bonded Particle Board (CBPB) as a specimen block which is made from the wood waste of carpentry work derived from Wood Machining Workshop in Politeknik Kota Kinabalu and to review the effectiveness of UCop. The features of CBPB are heavier than conventional composite but lighter than concrete, fire resistance, biological and weather resistance, aggressive to the environment, good heat insulation, high compression and good acoustics for absorbing sound.

The main function of UCop is as the spacer inside the reinforced concrete structures. UCop designs' greatly affect how the installation for each spacer block. UCop is in U-shaped accordance with the specification, set by the Public Works Department (PWD). It has two holes in the spacer block for the pin as a hanger and used bike rubber tube as a binder.

\footnotetext{
*Corresponding Author: Mohamed Bin Saim, Master Degree in Technique and Vocational Education, Lecturer, Department of Civil Engineering, Polytechnic of Kota Kinabalu, Sabah (PKK); research areas: civil engineering, wood based technology. E-mail: mohamed@polikk.edu.my
} 
UCop is an important tool in the construction industry where it used as a tool that retains reinforcement bar in its position inside reinforced concrete during the concrete pouring process. UCop remains beneath the reinforcement during the concrete pouring process and becomes part of the structure. UCop securely fastened to the reinforcement bar by a special binder which is using used bike tyre tube, without worry of it be sliding or tilting.

\section{Objective of Study}

The objectives of this project being carried out are to find an alternative design of concrete spacers that are more efficient in terms of installation method and also to prove that good quality materials can be made with low costs. From this study, the results showed that the installation of conventional concrete spacers take a long time depending on the size of the project and lead the construction of a structure not efficient in terms of time and cost. So, UCop may be a new alternative spacer block in future.

\section{Methodology of Study}

UCop made from the waste wood of carpentry work by using in particle size around $0.4 \mathrm{~mm}$ $2.00 \mathrm{~mm}$ which from a species of Shorea spp. (Seraya red and white) and mixed with Portland cement by a ratio 1:2.5 then added with Ammonia Chloride (Al2SO4) and Calcium Chloride $(\mathrm{CaCl} 2)$ act as additives to accelerate the drying process and for removing water vapor in the specimen block. CBPB production takes place for 1 day which is compressed

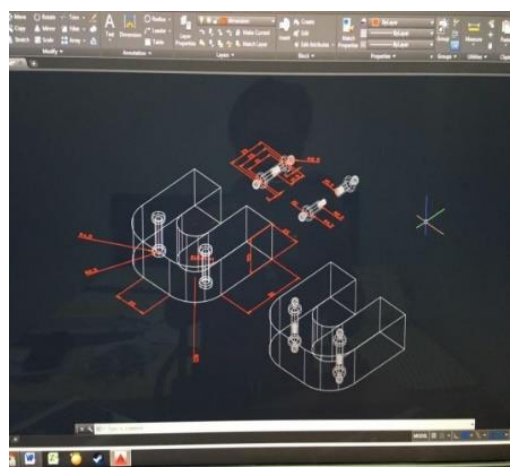

Figure 1 Prototype design by using Computer Aided Design (CAD) and the final product designed of UCop in cold press by using load 50 tons of hydraulic compressor machine for 24 hours then for curing process took 28 days naturally.

About 4 specimen blocks of CBPB successfully produced where one block is used for testing its level of physical strength (thickness expansion) and mechanical strength (bending strength). The location for produce CPBB was done at Carpentry Workshop of Civil Engineering Department in Politeknik Kota Kinabalu, Sabah. Cutting process of UCop samples were done at Malaysian Timber Industry Board (MTIB) Sabah region which located in Kota Kinabalu, Sabah with the size of each specimen block is $23 \mathrm{~mm} \times 23 \mathrm{~mm} \times 25 \mathrm{~mm}$ thick.

Two CBPB is used to produce UCop samples where each CBPB can produce as much as 6 UCop samples and each sample is cut according to the size of $75 \mathrm{~mm} \times 75 \mathrm{~mm}$. Therefore, the total of 12 samples of UCop can be generated. The process of making and forming UCop by using Grinder machine cutter, Disc Sander machine forming a U-shaped curve and Forstner bit $30 \mathrm{~mm}$ diameter is used to get a round shape or inner radius. The quantitative method chosen for the data collection was conducted using questionnaire.

Selective sampling method has been chosen for data collection by adopted questionnaire among 3 categories of respondent which were 20 experts from Sabah Public Works Department (PWD), 30 lecturers and 65 final semester students of Diploma in Civil Engineering, Politeknik Kota Kinabalu, Sabah. A total of eight (8) items for each first and second objective respectively evaluated as parameters.

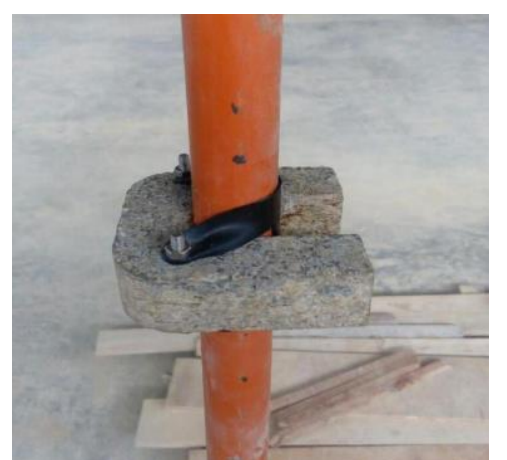

\section{Findings}

Based on the analysis through the 
questionnaire, found that overall respondents agreed that this innovative product meets the desired characteristics and fulfill its function as a spacer block yet the techniques and methods of installation made easier. In addition, expansion of thickness has reached the standards in MS934:1986 of 1.79\% on average. Meanwhile, the flexural strength did not reach the standard which is $2854 \mathrm{Nm}$ on average. The mixing method is a major cause of flexural strength not up to standard. As an improvement in future, the mixing machine should be used in mixing process in order to get the flexural strength that is up to standard.

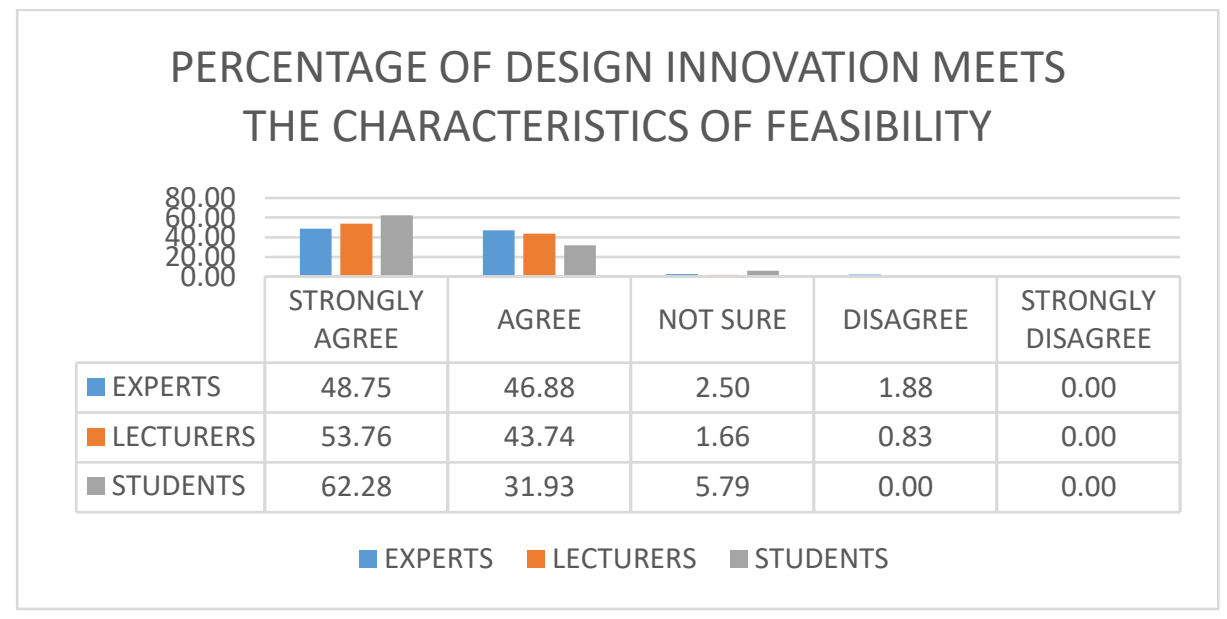

Chart 1 The Objective of Study 1

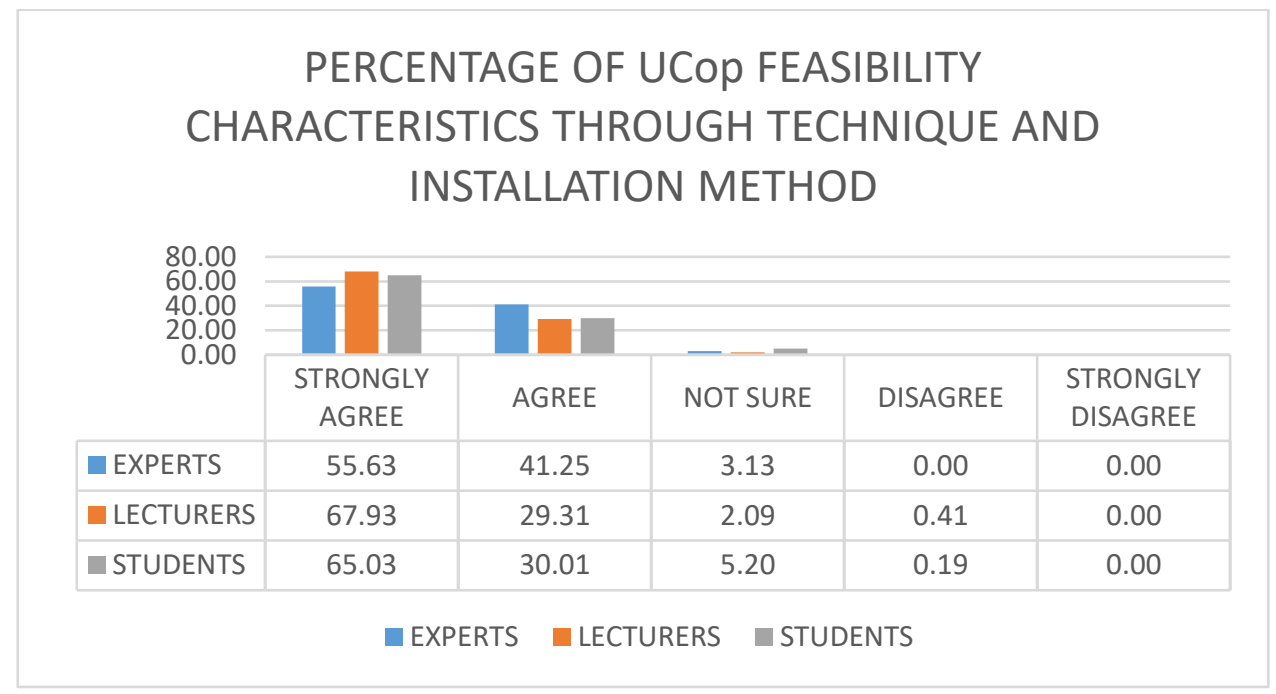

Chart 2 The Objective of Study 2

\section{Conclusion}

In conclusion, high impact innovation product in concrete construction can help the construction process done efficiently and construction costs can be minimized. Hence, it can be proved that all respondents agreed with UCop product design innovation. Thus, it can be said that researchers managed to achieve the objectives of the study. In addition, the preservation of nature can be applied by the use of wood waste as a raw material in the production.

\section{Acknowledgements}


This article was supported by Research and Innovation Centre, Department of Polytechnic Education (JPP), Ministry of Higher Education, Malaysia.

\section{References:}

[1] Frank, R. E. (1994). CONSTRUCTION AND DEMOLITION WOOD WASTE USED IN WOOD CEMENT COMPOSITES Introduction: Recycled Content: Considerations for Environmentally Sustainable Design and Construction :, 463-468.

[2] Wolfe, R. W., \& Gjinolli, A. (1997). Cement-Bonded Wood Composites as an Engineering Material. In The use of recycled wood and paper in building applications: Proceedings of a 1996 symposium sponsored by the U.S. Department of Agriculture Forest Service, Forest Products Laboratory, and the Forest Products Society, in cooperation with the National Assoc (pp. 84-91).

[3] Rex Miller, Mark Richard Miller \& Eugene Leger. (2004). Complete Building Construction. All New 5th Edition. Audel. [4] Wolfe, R. W., \& Gjinolli, A. (1999). Durability and Strength of Cement- Bonded Wood Particle Composites Made From Construction Waste. In Forest Products Journal (Vol. 49, pp. 24-31). 